Rowan University

Rowan Digital Works

Henry M. Rowan College of Engineering Faculty Scholarship

Henry M. Rowan College of Engineering

6-26-2016

\title{
An Adaptable and Transferrable Project Based on a Heart-lung Machine Design Challenge
}

\author{
Stephanie Farrell \\ Rowan University \\ Taryn Bayles \\ University of Maryland, Baltimore County \\ Patricia Kieran \\ University College Dublin
}

Follow this and additional works at: https://rdw.rowan.edu/engineering_facpub

Part of the Biomedical Engineering and Bioengineering Commons, Chemical Engineering Commons, and the Engineering Education Commons

\section{Recommended Citation}

Farrell, S., Bayles, T. M., \& Kieran, P. M. (2016). An Adaptable and Transferrable Project Based on a Heartlung Machine Design Challenge Paper presented at 2016 ASEE Annual Conference \& Exposition, New Orleans, Louisiana. 10.18260/p.26557

This Conference Paper is brought to you for free and open access by the Henry M. Rowan College of Engineering at Rowan Digital Works. It has been accepted for inclusion in Henry M. Rowan College of Engineering Faculty Scholarship by an authorized administrator of Rowan Digital Works. 


\section{An Adaptable and Transferrable Project Based on a Heart-lung Machine De- sign Challenge}

\section{Dr. Stephanie Farrell, Rowan University}

Dr. Stephanie Farrell is Professor of Chemical Engineering at Rowan University (USA) was the 2014-15 Fulbright Scholar in Engineering Education at Dublin Institute of Technology (Ireland). She obtained her $\mathrm{PhD}$ in Chemical Engineering from New Jersey Institute of Technology in 1996. Dr. Farrell has contributed to engineering education through her work in experiential learning, focusing on areas of pharmaceutical, biomedical and food engineering. She has been honored by the American Society of Engineering Education with several teaching awards such as the 2004 National Outstanding Teaching Medal and the 2005 Quinn Award for experiential learning. Stephanie has conducted workshops on a variety of topics including effective teaching, inductive teaching strategies and the use of experiments and demonstrations to enhance learning.

\section{Dr. Taryn Melkus Bayles, University of Maryland, Baltimore County}

Taryn Bayles, Ph.D., is a Professor of the Practice of chemical engineering in the Chemical, Biochemical, and Environmental Engineering Department at UMBC, where she incorporates her industrial experience by bringing practical examples and interactive learning to help students understand fundamental engineering principles. Her current research focuses on engineering education, outreach and curriculum development.

\section{Dr. Patricia M Kieran, University College Dublin}

Dr. Patricia Kieran is a Senior Lecturer in Chemical \& Bioprocess Engineering at University College Dublin. Graduating from UCD (1985), she received an MS in Chemical Engineering from the University of Missouri-Rolla (1986) and a PhD from UCD (1996). She was appointed as a UCD Fellow in Teaching \& Academic Development (2007) and as a Senior Fellow in 2009. She is a 2009 recipient of an ExxonMobil Award for Excellence in Engineering Teaching. 


\title{
An adaptable and transferrable project based on a heart-lung machine design challenge
}

\begin{abstract}
A heart-lung machine is used to take over the function of the heart and lungs during a surgical procedure in which the heart must be stopped. This machine makes possible a variety of lifesaving surgeries such as heart transplants, bypass surgery, and valve replacement. Blood oxygenators are used in more than one million procedures annually, and their total market is over $\$ 500$ million per year. This paper describes how a heart-lung machine design challenge was used in four different educational contexts: high school science courses in the United States, a multidisciplinary first year engineering course at a university in the United States, a second year chemical \& bioprocess engineering course at a university in Ireland, and an upper level chemical engineering core course (Transport II). The design challenge required students to design, build, and test a heart-lung machine to simulate the performance of a clinical cardiopulmonary bypass system. The project proved to be adaptable and transferrable to different contexts with different learning objectives, assessment, instructional strategy, student population, and details of implementation.
\end{abstract}

\section{Introduction}

\subsection{Biomedical Education}

Biomedical engineering is a relatively new, interdisciplinary field existing at the intersection of life science, medicine, and engineering. An aging population and increasing focus on health issues are accompanied by a rapidly increasing demand for improved medical equipment and devices. According to the Department of Labor Statistics, Biomedical engineers are expected to have employment growth of $23 \%$ between 2014-2024, in comparison with the average of $7 \%$ for all occupations [1]. Biomedical engineering is the most rapidly growing discipline at most universities [2]; although many biomedical engineers obtain a bachelors degree from an accredited biomedical engineering program, a viable alternative relies on an undergraduate degree in a traditional engineering discipline complimented by technical electives related to biological sciences [1].

Chemical, mechanical, and electrical engineers play a key role in this promising field because the core disciplinary principles are critical to biomedical interests such as the design of artificial organs. In an international study of career preferences of chemical engineering students, bioprocess and biomedical industry received the highest ranking by a large margin in Australia and New Zeland, Canada, the United Kingdom and the United States [2].

This paper describes a project in which students are introduced to engineering principles through the design of a heart-lung machine. In a hands-on, team-based experience, students participated in designing, building and testing their own heart-lung systems made from inexpensive, readily available materials. Its implementation in four different contexts is described: high school 
science courses in the United States, a multidisciplinary first year engineering course at a university in the United States, a second year chemical \& bioprocess engineering course at a university in Ireland, and an upper level chemical engineering core course (Transport II).

\subsection{Cardiopulmonary Bypass}

Over one million cardiopulmonary bypass procedures are performed each year [3] for surgeries including heart transplantation, coronary artery bypass, valve repair or replacement, and aneurysm repair [4]. In cardiopulmonary bypass, also known as extracorporeal circulation, the heart and lungs are temporarily removed from the circulation system. A heart-lung machine performs the function of the heart and lungs allowing the heart to be still during the surgical procedure.

Heart-lung machines have four functions: They pump the blood, oxygenate the blood, partially remove carbon dioxide from the blood [5], and regulate the temperature of the blood [6]. Figure 1 shows the cardiopulmonary functions performed by a heart lung machine.

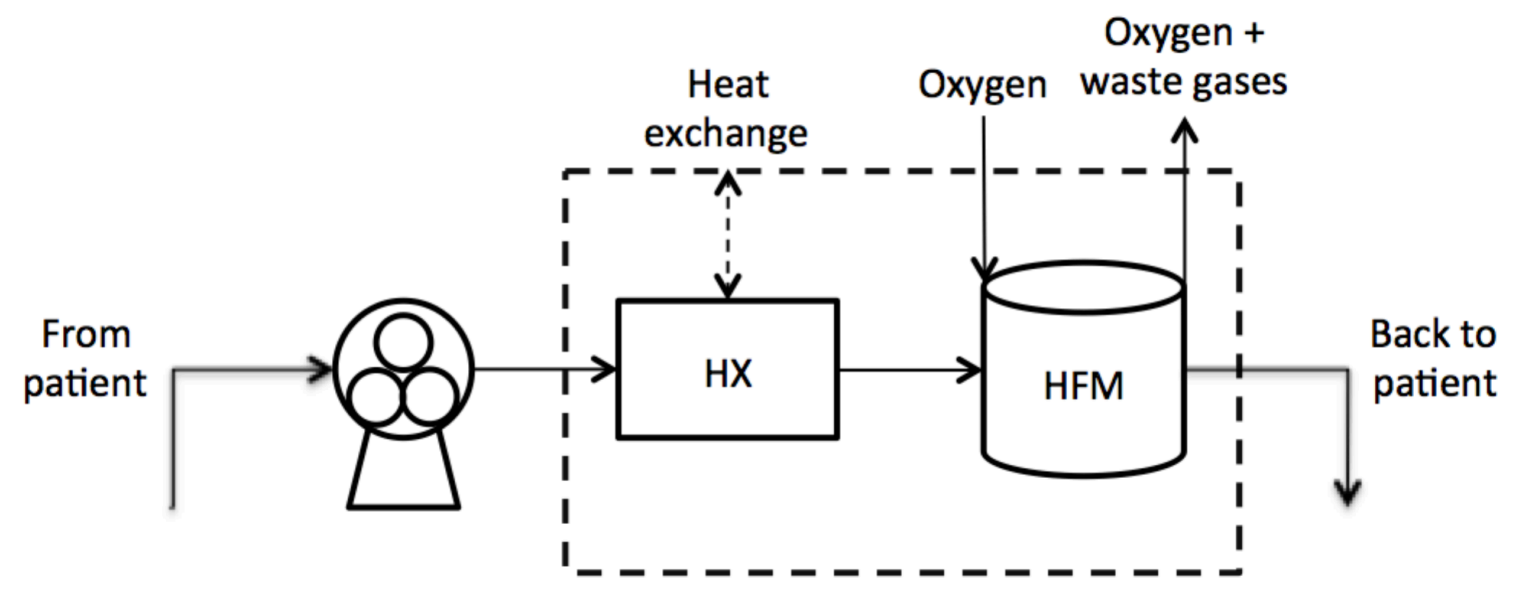

Figure 1 - Unit operations in a heart-lung machine. Gas transfer is accomplished via membrane oxygenators, which have largely supplanted the bubble oxygenators used in early CPB systems in the United States [7], but are still used elsewhere. Heat exchange (HX) is required to counter heat loss to surroundings and maintain the blood temperature. Heat exchanger and membrane are commonly combined into a single, disposable unit [4]. Flow diagram taken from [8].

Cardiopulmonary bypass systems circulate blood throughout an extracorporeal circuit at a typical flow rate of $2-4 \mathrm{~L} / \mathrm{min}$ for normothermic operation [9]. From the body, blood is gravity-drained into a venous reservoir placed $40-70 \mathrm{~cm}$ below the level of the heart [10]. The typical volume of the reservoir is $0.5 \mathrm{~L}$, and the total extracorporeal blood volume must be below 1-3 L [10]. Positive displacement roller pumps and centrifugal pumps are the two most common types of pumps used for CPB. The advantages and disadvantages of roller pumps and centrifugal pumps are reviewed by [11] .

Early heart-lung machines relied on bubble oxygenators to control blood gas levels. These have largely been supplanted by membrane oxygenators in the United States [7], although bubble 
oxygenators continue to be used elsewhere for their cost-effectiveness. Blood oxygenator membrane units are flat or hollow fiber membrane (HFM) units with at least $1 \mathrm{~m}^{2}$ of surface area $[9,12]$.

During bypass surgery on a typical adult patient, approximately $200 \mathrm{~cm}^{3}$ (STP) $\mathrm{CO}_{2} / \mathrm{min}$ must be removed from the blood and $250 \mathrm{~cm}^{3}$ (STP) $\mathrm{O}_{2} / \mathrm{min}$ must be transferred to the blood [13]. A heat exchanger is used to regulate the temperature of the blood, to maintain the temperature at regular body temperature of $34^{\circ} \mathrm{C}-37^{\circ} \mathrm{C}$ (normothermic) for some procedures, or to reduce the temperature to hypothermic $\left(<34^{\circ} \mathrm{C}\right)$ for other procedures [14]. Normothermic operation is associated with increased oxygen demand [15].

\section{Implementation}

\subsection{Pedagogical Framework}

Within an engineering context, Felder and Prince [16] present strong evidence that inductive teaching methods are more effective than traditional deductive teaching methods. Their review of inductive methods includes case studies, discovery learning, project-based learning and problem-based learning. In comparison to traditionally-taught students, students who participate in project-based learning are more motivated, demonstrate better communication and teamwork skills, and have a better understanding of issues of professional practice and how to apply their learning to realistic problems [17-19]. The process of "guided discovery", in which students are presented with a problem to solve and supported in their discovery and interpretation is an effective pedagogy for enhancing learning within a project-based setting [20].

The different implementations of the Heart-Lung Project described below are all strongly rooted in inductive pedagogy. The high school implementation (context 1) utilizes a more structured, guided inquiry approach, whereas the university implementations utilize a problem-based learning approach. The specific approaches are described in more detail below for each context.

\subsection{Educational Context}

\subsubsection{Context 1: High School in the United States}

The INSPIRES Curriculum (INcreasing Student Participation Interest and Recruitment in Engineering and Science) is comprised of five standards-based modular units for grades 9-12 that focus on integrating all areas of STEM. The approach uses real-world engineering design challenges and inquiry-based learning strategies to engage students, increase technological and scientific literacy, and develop key practices essential for success in STEM disciplines. The curriculum is designed to be flexible and cost effective to maximize potential usage. Modules are independent of one another, so they can be implemented individually in an existing science or technology education course, or together in a cluster, to comprise a full course. In the high school setting, each module is 4-6 weeks in length (assuming 45 minute class periods) and includes hands-on activities, digital resources and a real-world open-ended engineering design challenge. P21 skills (critical thinking and problem solving; communication and collaboration; and creativity and innovation) are central to the INSPIRES approach. The curriculum is aligned to the Next Generation Science Standards.

Design Challenge. Each unit includes an overarching, open-ended engineering design challenge that focuses on a real-world problem or need. The design challenges are written with quantitative design criteria and constraints and require students to make decisions about tradeoffs 
as they move through the design process. The challenges are designed to have enough specificity to allow solution within a week to two weeks of class time, but are open-ended enough to allow for significant creativity in the design solution. The original problem statement for the Heart-Lung project is provided in Box 1.

\section{Box 1. The original Heart-Lung Problem Statement.}

Your team is to design, construct, test, and evaluate a system that will simulate the performance of the heart and lungs in the human circulatory system. Your goal is to flow the 'blood' through your system which is required to oxygenate and cool the 'blood' while minimizing leaks and the amount of 'blood' within your system. You will be allotted 5 minutes to setup the system at the test site and it must fit within the specified area. You will then have 15 minutes to process the 'blood' and to achieve specified performance criteria. All team members must be present during the system testing / evaluation. You are encouraged to check your design well in advance of your testing / evaluation date. When you have completed the evaluation, deconstruct it and return all borrowed parts.

\section{Your primary criterion for this design project is SAFETY. Your system must operate without any hazards. Keeping SAFETY in mind, the following restrictions are placed on the design:}

- Your team must provide and justify all of the components of your system.

- The system will be tested using a volume of 5 liters of 'blood'.

- The maximum amount of 'blood' in your heart-lung system (including any 'blood' lost via leaks from the system) is 1.5 liters.

- The system should maximize the oxygenation of the 'blood' - the minimum increase of dissolved oxygen content must be at least $3 \mathrm{mg} / \mathrm{L}$.

- The system must also cool the 'blood' - Your team will select and justify a range of temperature change to achieve during the design and testing phase. On the day of the demonstrations, a clinically reasonable target temperature change will be specified.

- Your team must select and justify an appropriate range of flow rate for the system. Your team will have a variety of pumps to use during testing (the cost of these pumps will not be included in your system cost).

- The cost of your system must be less than $\$ 50.00$ (all materials used in your design are considered to be purchased new, as if you were prototyping the device for production - i.e., even if you use 'found' materials, you must cost them as if they were new). Non-functional decorations do not need to be included in the cost (i.e., paint, marker, stamps, decals, etc.). 
Lesson Plans. Complete lesson plans for each unit include detailed instructions for presenting content and doing hands-on activities, and suggest appropriate pedagogical strategies throughout. Student handouts and worksheets are included to facilitate instruction.

Classroom Display. Electronic files suitable for printing at poster size for classroom display are available, including the "Engineering Design Loop" and a "Design Target" specific to each unit.

Video Content. The curriculum uses professionally produced video segments to introduce students to the real world application and societal need behind each engineering design challenge. Videos are also included to introduce students to career pathways related to the unit content.

Online Animations and Mathematical Simulation. All units include an online mathematical simulation that allows students to vary parameters specific to the design challenge. In doing so, students explore quantitatively how these changes affect system performance. Selected units also include online animations that allow students to visualize molecular level phenomena responsible for macroscopic behavior.

Assessments. The curriculum includes end-of-unit multiple-choice tests to assess student learning of engineering and science concepts. These tests can also be given before a unit, if evidence of student growth is required. Scoring guides for assessing individual and team performance on engineering design tasks are also included in the curriculum materials.

Laboratory Equipment and Supplies. The INSPIRES Curriculum is designed as a low-cost solution to integrating engineering into the high school classroom. The curriculum does not require the purchase of expensive core equipment and relies heavily on common science lab supplies and materials often found in art rooms or woodshops. Most materials needed to complete the units are available through retailers such as Wal-Mart ${ }^{\mathbb{R}}$, Target $^{\circledR}$, Radio Shack $^{\circledR}$, Home Depot ${ }^{\circledR}$ and Lowes ${ }^{\circledR}$. Recycled and common materials are used as much as possible.

Engineering in Healthcare: A Heart Lung Case Study [21]

This introductory video focuses on a teenage girl who was born with a heart defect and needed a lifesaving open-heart surgery. The video describes her treatment, introduces her doctor, and explains the function of the heart lung machine (Context). Student teams are given the challenge to design, build, test and refine a system that mimics attributes and functions of a heart lung machine, which must circulate the 'blood' at an appropriate flow rate, oxygenate the 'blood' and cool the 'blood'. Design teams are challenged to maximize efficiency while minimizing system cost. The maximum system cost is set at \$50 (STEM Practices). After watching the video and receiving the challenge, students use a "Think, Pair, Share" strategy to reach consensus (Collaboration) on key ideas as well as the criteria and constraints required to construct a design solution.

As students attempt to solve the design challenge, they are introduced to the engineering design process as a rational and methodical cycle of steps (STEM Practices). The various steps are explicitly addressed during the lessons to ensure that students understand each process they use (Metacognition). A large classroom poster is used to facilitate these explicit connections (Public Artifacts). In order to understand the various design constraints and criteria as well as 
make informed design decisions, the students learn relevant scientific principles as well as mathematical equations to quantitatively assess and refine their design (Standards Based).

In this module, students learn concepts associated with (1) anatomy and physiology of the heart and lungs, (2) heat transfer, (3) oxygenation and (4) fluid flow/flow rate/pumps. These science concepts are introduced in the curriculum through a variety of "just in time" phenomena-first activities (Context) and inquiry-based investigations (STEM Practices). First, student teams are presented with a mini design challenge in which they must design and test a system that can transport $500 \mathrm{~mL}$ of water a distance of six feet with minimal leakage in the quickest possible time. This hands-on exercise is used to introduce the concept of fluid flow in a way that is visual to the learner. It is also used to reintroduce the engineering design process

(Context/Standards). Prior to receiving teacher approval to start device construction and testing, individual group members submit potential design solutions, then engage in small discussion to build consensus (Collaboration) on a prototype design. Group presentations of designs and design decisions link the exercise to the overarching heart lung system design challenge.

Students then learn more about the pumps, heat transfer and oxygenation through a series of hands-on exercises. Finally, students investigate ways to make fluid flow and learn how fluid flow is measured and described quantitatively. Following hands-on exploration, students use online models and animations to illustrate the "non-visible" mechanism(s) driving many of the observed macroscopic events. Concepts of molecular motion and heat transfer are stressed, linking the online visualization to the hands-on activities. Computer-based mathematical simulations are utilized prior to the final design and build phase allowing students to alter a variety of design parameters and quantify their impact on the system efficiency (STEM Practices). Students then plan, build, test and refine a "heart lung system" (Integrates all principles). Student teams present their final designs along with an analysis of design decisions in an open forum (Collaboration/Public Artifacts). Concepts and key ideas are reinforced and continuity between lessons is maintained through the use of a design notebook. In the notebook, students record daily artifacts representing their understanding (Metacognition) that are publically displayed on a classroom artifact board (Public Artifacts).

To date, the INSPIRES Heart Lung system curriculum has been used by over 35 science (Biology, Chemistry, Physics) and technology (Engineering, Pre-Engineering, Allied Health and Technology Education) teachers impacting more than 1000 students in the mid-Atlantic region.

\subsubsection{Context 2: First Year Engineering Course at a University in the United States}

The project was the basis of a course called Freshman Engineering Clinic at Rowan University. This two credit-hour course is offered in the fall and spring respectively. The class has two meetings per week, once in a classroom for 50-minutes, and once in a laboratory for 165minutes. Students from Rowan University's five engineering disciplines - Biomedical, Chemical, Civil, Electrical and Computer, and Mechanical - are enrolled in the course and distributed into multidisciplinary sections. There are currently 16 sections of the course offered with approximately 18-24 students in each section. Students work in teams on a semester-long, multidisciplinary project that introduces a variety of introductory engineering topics and requires the application of science and mathematics concepts. While each instructor is free to choose a different project and pedagogical implementation, the common technical topics include unit 
conversions, statistics, problem solving, engineering design, and safety. Ethics, teamwork, and communication are also emphasized in this course.

After learning about the INSPIRES Heart-Lung project at the ASEE 2012 Chemical Engineering Summer School, Rowan University adapted the project for use in Freshman Engineering Clinic I in the fall semester that year. The overarching goal of this project was to motivate and excite students about engineering through an integrated learning experience that enhances affective and cognitive learning. The project aimed to instill a positive perception of engineering work and increase students' appreciation for the historical, social and personal relevance of engineering. At the end of the project students should understand the role of open-ended design projects with multiple possible solutions in engineering work. The project was intended to raise awareness for career opportunities in biomedical engineering.

In addition to achieving affective learning described above, the following learning outcomes are related to engineering design:

- Define engineering and medical terminology relevant to mass transfer in heart-lung systems

- Apply a mass balance to determine the rate of oxygen transfer to the blood

- Apply an energy balance to calculate the rate of heat transfer from the blood

- Predict the effect of flow rate and tubing material on heat transfer rate

- Predict the effect of liquid flow rate on oxygen transfer to the blood

- Evaluate design alternatives related to components and operating conditions of a heartlung system

- Synthesize understanding of medical, science, and engineering knowledge into design and operation of a heart-lung system

The Rowan University project, currently in its third iteration, is currently implemented using a problem-based learning framework. After receiving an initial problem statement of an illdefined, open-ended problem, students proceed through cycles of information seeking, scientific inquiry and design-build-test interspersed with small- and large-group discussions that allow groups to construct an understanding of underlying engineering principles that inform their design. In the PBL version of the project, the functions of a heart-lung machine were not provided in the problem statement; rather, they were constructed by the class during a discussion on the first day. Subsequently, students sought information that allowed them to establish quantitative criteria and constraints for their problem. The temperature, flow, and oxygenation specifications were determined through subsequent inquiry cycles instead of being specified in the initial problem statement.

Thus, the 14 modules of the original Heart-Lung project were collapsed into three main cycles defined by themes of fluid flow, heat transfer and mass transfer. In a 15 week semester, 12 
laboratory periods were used for lab activities, and one laboratory period was used for each of an introduction, a midterm exam, and final presentations.

In order to provide some exposure to cutting edge technology using laboratory equipment, the Rowan University project added a hands-on introduction to science and engineering principles using a laboratory blood oxygenation system using a hollow fiber blood oxygenator. This experiment provided a greater range of measurement and flow control options that allowed a more in-depth investigation of mass transfer than was possible using the systems built by the students; students also learned about different measurement techniques and hollow fiber blood oxygenator design during this experiment. This experiment and its impact on student learning is described elsewhere [8].

\subsubsection{Context 3: Sophomore Chemical Engineering Course at a University in Ireland}

At University College Dublin, the heart-lung machine project has been implemented within the second year of a 4-year degree program in Chemical \& Bioprocess Engineering. (This program is professionally accredited, at Master's level, by the Institution of Chemical Engineers (IChemE), UK). All University College Dublin Engineering freshmen follow a largely common curriculum, only choosing to specialize in particular engineering disciplines at the start of their second year and Chemical \& Bioprocess Engineering has an intake of 40-50 students per annum. Group-based, problem-based learning (PBL) has been a feature of the Chemical \& Bioprocess Engineering curriculum since 2008, with the introduction of a heat exchanger design project, based on an activity originally developed by Davis [22]. As at Rowan University, PBL has been used at University College Dublin as a vehicle for allowing students to explore and apply key engineering concepts and tools, to develop student proficiency in professionally-relevant, transferrable skills and to excite students about their discipline.

As a result of the 2012 INSPIRES presentation at the ASEE Chemical Engineering Summer School and with subsequent support from Rowan University, a PBL project based on the heartlung machine was developed; the pedagogical approach was very similar to that at Rowan University. During the 2014-15 academic year, the heart-lung machine project was a compulsory student activity, associated with two core, co-requisite, 5-credit, Semester 1 modules: CHEN20020 - Chemical \& Bioprocess Engineering Measurement; CHEN20040 Chemical \& Bioprocess Engineering Laboratory 1. (Within the European Credit Transfer System (ECTS), a full academic year of study is equivalent to 60 credits.) The class of 42 students was divided into 10, mixed-ability teams of 4-5. The project was led by one instructor, one Teaching Assistant and one Technician. Design-related activities, concentrated in weeks 1-6 of the 12week teaching semester, were chiefly associated with CHEN20020 and accounted for $20 \%$ of the module grade; construction, testing and final reporting, focused in weeks 7-12, accounted for $25 \%$ of the CHEN20040 module grade. Two consecutive, 50-minute sessions were scheduled for the PBL project each week: in weeks 1-4, one period was allocated to a structured, instructorled session, the other was available for student-led work, for formal team review meetings with the instructor or for other, project-relative activities. (Previous experience with PBL projects had highlighted the importance of providing students with both a scheduled time and an appropriate venue for collaborative work.) Throughout the semester, 1-hour, laboratory-based sessions were allocated to investigation and hands-on characterization of available aeration and pumping systems and associated equipment and instrumentation. During weeks 9-10, each team was allocated to a 1-hour system construction session and a 1-hour system testing session. A design 
report was submitted in week 7; the Final Report and a technical poster were submitted in week 13.

At University College Dublin, the heart-lung machine project currently meets a curriculumspecified PBL project requirement. Thus, learning outcomes are expressed more generically than at Rowan University, so as to be applicable to other PBL projects. On completion of the CHEN20020 (design-related) elements of the project, students should be able to:

- Effectively undertake independent study, in a discipline-related topic;

- Work effectively, as a member of a team, in the design of a simple piece of process equipment, with due consideration of safety, environmental and economic considerations.

- Collate and meaningfully present engineering information, adhering to standard conventions of technical reporting.

On completion of the CHEN20040 module (which includes formal laboratory experiments, in addition to the construction, testing and reporting phases of the PBL project), students should be able to:

- Demonstrate knowledge and understanding of good laboratory practice, particularly with regard to safety, health and the environment.

- Work effectively, with an assigned partner(s), in undertaking Chemical/Bioprocess Engineering experiments.

- Analyze experimental data, critically evaluate experimental results and effectively communicate the results in written reports.

- $\quad$ Read, construct, and explain to others, simple Process Flow Diagrams (PFD) and Process/Piping \& Instrumentation Diagrams (P\&ID).

- Work as a member of a team in constructing, testing, evaluating and reporting on a simple piece of process equipment.

\subsubsection{Context 4: Completion of third year chemical engineering courses}

The INSPIRES Heart Lung system design challenge was first tested with freshman engineering students at the UMBC in an introductory engineering design course. This first year course is a mixed lecture/lab course like that described in context 2 above; however, the emphasis here is on a reflective activity that took place two and a half years later, after the same students had officially matriculated into the chemical engineering program and completed their junior level courses in Transport Phenomena I (Fluids) and II (Heat and Mass Transfer). As part of their Transport Phenomena II class, the students were given their original freshman engineering design reports and were required to provide an analysis of their design. The analysis assignment was two-fold: the students were required to submit a group report re-analyzing the technical merits of their heart-lung design project and the students were required to submit an individual reflection paper. The group report analysis included: significance of design criteria, engineering 
design process and theoretical analysis of data collected. The idea behind the reflection assignment was to help the students clarify what they have studied and learned, integrate new knowledge with previous knowledge, as well as to help them become an active and aware learner so that they can better understand how they learn. Their reflection topics included: the engineering design process, engineering/math/science connections and technical writing [23].

\section{Assessment}

\subsection{Context 1: High School}

The INSPIRES curriculum features an online system includes pre/post tests which the students complete individually; this data has been used to assess student learning of key science and engineering and has shown that student have achieved significant learning gains in both areas. In addition, interest and attitude data is also collected pre/post of the module completion. These results for the Heart Lung system have been previously presented [21] in detail, but a summary is presented here for convenience. The mean score on engineering concepts increased from $37.5 \%$ $( \pm 1.1 \%)$ on the pre-test to $49.3 \%( \pm 1.1 \%)$ on the post-test, and the mean score on key science concepts increased from $50.6 \%( \pm 1.1 \%)$ to $63.3 \%( \pm 1.2 \%)$. A two-tailed test showed that there was a significant difference between means on the pre-test and post test for both key engineering concepts $(\mathrm{p}=1.8 \mathrm{e}-30)$ and key science concepts $(\mathrm{p}=1.9 \mathrm{e}-22)$.

Students also completed an Interests and Attitudes survey before and after participating in the heart-lung project. Statistical differences between pre-test and post-test were found for ten of the fifteen survey questions. The gains pertained to aspects related to students perceived understanding of the design process, perceived understanding of engineering concepts and scientific terminology, and confidence in engineering skills. More detail is available in the article by Vonder Haar et al. [21].

In a Post-module questionnaire, students were asked whether their interest or skills in specific areas increased, decreased or remained the same as a result of the project. Students rated the project very favorably in terms of having increased their confidence and understanding of engineering and technology topics. For example, over $53 \%$ of the students reported an increase of their ability to work in teams, knowledge of how math helps solving problems, knowledge of engineering or technology fields and understanding of the engineering design process as a result of using the curriculum module. Further detail on the post-module questionnaire results was reported previously [21].

\subsection{Rowan University}

Rowan University's assessment of cognitive and affective learning resulting from this project used two main sources: (1) final design reports and (2) the Pittsburgh Freshman Engineering Attitude Survey (PFEAS). A detailed discussion of final design reports is provided elsewhere [4], and therefore only a summary is presented here [8]. This paper focuses on the results of the PFEAS from the year 2013.

The PFEAS is a validated survey that has been used extensively in the United States to measure students' interests, confidences, experiences and perspectives of engineering from 20 aspects. Seven questions specific to biomedical engineering were added to the survey for the purpose of this project. The survey was given to all engineering students at the beginning and the end of their first semester. The 4 sections performing biomedical experiments were treatment sections, 
and the remaining sections were the comparison sections. On the pre-test, no significant difference was shown across the twelve sections in any of the 20 aspects of the survey. On the post-test, the biomedical treatment group scored significantly higher in the following aspects:

- Perception of classroom climate

- Interest and confidence in biomedical engineering

- Confidence in engineering

- Confidence in writing

- Perception of engineers' contribution to society

Further, the biomedical treatment group scored significantly lower on their perception of engineering as an exact science, which could reflect their understanding of multiple solutions to engineering problems.

One of the class sections that was part of the biomedical treatment group performed a shorter project than the other three sections that performed the full semester project. The treatment group data cannot be disaggregated because the researchers have access only to the aggregate data. This is a limitation of this analysis.

Students' design reports were evaluated on the following technical performance indicators, using a 4-point Likert scale:

- Applied knowledge of heat transfer, mass transfer, fluid flow to the solution of an engineering problem

- Identified realistic constraints in the following categories: economic, ethical, and medical

- Developed technically feasible alternative solutions

- Analyzed solution using engineering principles

- Compared and evaluated alternative solutions using criteria and constraints

- Recommended one of the solutions

In the first year the project was implemented, student learning outcomes were good and interest was high. However, an area of improvement was identified in students' ability to synthesize their understanding of scientific/engineering principles into their design. The next time the course was offered, a laboratory heart-lung mass transfer experiment was added to emphasize the importance of science and engineering principles to engineering design. A positive shift in all of the above performance indicators was observed. The results are described in more detail in [8].

\subsection{ABC University}

Student performance in the heart-lung machine project was assessed as part of two separate modules: a formal Design Report was submitted in week 7, as part of CHEN20020; a Final 
Report and a technical poster were submitted in week 13, as part of CHEN20040. A collective grade was assigned to each team based on work associated with the project; individual contributions were weighted via peer assessment, implemented using WebPA, an open-source, online tool, developed at Loughborough University (http://webpaproject.lboro.ac.uk). Core engineering concepts explored through the heart-lung machine project featured in questions in the CHEN20020 end-of-semester test (which accounts for $70 \%$ of the module grade); this approach facilitated assessment of individual student level of achievement of specific learning outcomes, through largely self-directed learning and/or open-ended practical sessions, associated with the Heart-Lung project.

Since the introduction of PBL as part of the sophomore curriculum at University College Dublin, PBL-specific feedback has been solicited within the end-of-semester, University-wide student survey of all University College Dublin, modules. Semester $12014-15$ feedback for CHEN20020 and CHEN20040 (with response rates of 48.8\% and 41.9\%, respectively), indicated a high level of student overall satisfaction with both modules, with 5-point, Likert-scale scores of 4.14 and 4.17, respectively, compared to an average overall satisfaction score of 3.89 for all Chemical \& Bioprocess Engineering modules offered that semester. The statement 'Teaching on this module supported my learning' yielded scores of 4.62 for CHEN20020 and 4.24 for CHEN20040, compared to an average of 3.88 for all Chemical \& Bioprocess Engineering modules. Associated, open-ended comments on the 'effectiveness of the PBL project...in supporting your Chemical Engineering learning’ were almost exclusively positive:

- "It gave me more knowledge about the actual work of engineers - team work, new ideas, problem-solving..."

- "a good way to begin my first "real" research on a topic...I wasn't being spoon-fed information"

- “...very interesting. Not only we were able to design something, but this module gave us an opportunity to test and identify the flaws."

- "...the heart-lung project greatly aided the learning of theory from this module and it proved very useful when studying for exams."

Even less positive comments (primarily related to project time commitment and inequality of student contributions to the collective team effort) reflected student awareness of associated learning gains, e.g.

- "Although teamwork felt like the greatest scourge, it's valuable to have the experience of working with a team, particularly in the context of design and report-writing. It's a valuable lesson to learn what dynamic you fit into in a team and how you can work to improve and work more effectively in teams...having a high/low GPA doesn't always mean you're a good/poor worker and certainly doesn't say anything about your ability to work effectively on a team...peer assessment was also a fantastic idea feedback...should be mandatory to justify the marks given to each student."

Feedback from employers recruiting for Summer/year-long engineering internships indicates that third Year students (who, typically, have no prior professional work experience) draw heavily on 
their PBL experiences in responding to competency-based interview questions requiring evidence of teamwork, problem-solving, independent learning, communication and technical skills. During Autumn 2015, interviewers with experience of University College Dublin Chemical \& Bioprocess Engineering students over several recruitment cycles commented specifically on heightened student enthusiasm for the heart-lung machine project, awareness of the practical applications of engineering theory (particularly transport phenomena), an impressive appreciation of the complexity of the design process and a more mature approach to team work.

A portion of the PFEAS was administered, post-project, at University College Dublin and taken by $37(88 \%)$ of the original 42 students. The survey reveals high levels of student motivation in studying engineering and awareness of the value of engineering careers:

- "I expect that engineering will be a rewarding career": 100\% Agree/Agree strongly

- "The future benefits of studying engineering are worth the effort": $94.6 \%$ Agree/Agree strongly

Students were then asked to 'rate the degree to which you agree or disagree' with each of a series of statements 'based on how the heart-lung machine project contributed to your understand/belief'. On general perceptions of engineering (e.g. "I feel I know what an engineer does": $67.5 \%$ Agree/agree strongly"), there was a greater spread of responses, than to the preceding questions, possibly attributable to the fact that the University College Dublin students, mid-way through the second year of full-time engineering studies had the benefit of a wider range of academic and life experiences than freshmen, thereby reducing the impact of the heartlung machine project on their perceptions. However, the heart-lung machine project appeared to impact heavily on their understanding of their own abilities in specific skillsets employed for the project:

- "I have strong problem-solving skills": 78.4\% Agree/Agree strongly

- "I enjoy solving open-ended problems": 83.78\% Agree/Agree strongly

- "I enjoy problems that can be solved in different ways": 89.2\% Agree/Agree strongly

Participation in the heart-lung machine project also increased student knowledge of biomedical engineering:

- "I know more about the field of biomedical engineering after completing this project": 78.4\% Agree/Agree strongly

However, its impact on student levels of interest in biomedical engineering was less pronounced:

- "I think I would feel fulfilled working on biomedical engineering applications": $48.7 \%$ Agree/Agree strongly

- "I have interest in exploring biomedical engineering-related work": $62.2 \%$ Agree/Agree strongly 
- "I think I would like to work on more projects with biomedical engineering applications": 47.2\% Agree/Agree strongly

These results are unsurprising from a cohort of students who have actively selected to enroll in Chemical \& Bioprocess Engineering, as opposed to any of 6 other engineering disciplines including Biomedical Engineering - offered at University College Dublin. The students strongly identify with Chemical \& Bioprocess Engineering and viewed the heart-lung machine project as a vehicle for applying Chemical \& Bioprocess Engineering principles.

\subsubsection{Context 4: Third Year Chemical Engineering Core Course at UMBC}

Third year chemical engineering students enrolled in the required course Transport II (Heat and Mass Transfer) completed the reflective writing assignment at the end of this spring semester course. The assignment was worth $10 \%$ of their course grade. The assignment had a team component and an individual component. The team assignment was for each team to analyze their first year heart-lung design report and to address the following aspects of their work:

- Significance of the design criteria (testing volume, system volume, flow rate, oxygenation, cooling)

- The engineering design process

- Analysis of the data collected (comparing predicted to actual values of heat transfer rate, mass transfer rate, fluid flow rate).

The individual assignment asked students to reflect on:

- The engineering design process

- Connections between engineering, math and science

- Technical writing

The writing assignments allowed students to think critically about their early engineering work, which provided an opportunity for them to become more aware of their learning processes during three years of engineering study. The additional engineering experience allowed students to identify some of the weaknesses of their early work. These results were originally reported by Bayles [23], but some of the key themes to emerge are summarized below for convenience.

- A lack of consideration for physiological constraints in their design criteria: blood volume, system volume, flow rate, oxygenation, and cooling requirements (team assignments)

- Reliance on trial and error solutions rather than an engineering design process (team assignments)

- A lack of attention to aspects of technical report writing (format, style, mechanics, organization (team assignments) 
- A better appreciation for mathematics and science (individual reflection)

- An awareness for how much they have learned

- An appreciation for how much they still need to learn (individual reflection)

A course survey was administered at the end of the course and used to explore student selfassessment of their progress through the curriculum. The survey was given to an experimental group that performed the reflective writing assignment and to a comparison group from the previous year that did not complete the reflective writing assignment. The survey addressed the course objectives as they align with with ABET criteria (the five C's - Competency in the discipline, Critical thinking ability, the ability to work in Cooperation with teammates, effective Communication skills and Capacity for life-long learning). A significant difference was observed between the mean response in the following categories:

- Ability to design process using engineering principles

- Ability to evaluate solutions or designs given constraints

- Ability to analyze data to solve an engineering problem

- Ability to assess your own ability/knowledge to solve a problem and determine when to seek help

\section{Conclusion}

This paper describes how a heart-lung machine was used as the basis for engineering projects in three different educational contexts, spanning high school, first year engineering, a sophomore level core chemical engineering course, and an upper level chemical engineering core course. Each context required adaptation of the project objectives to meet curricular standards (high school) or program and accreditation requirements (university). The different implementations of the project used different pedagogical strategies that were appropriate for the desired learning outcomes. Each context also required development of an assessment plan that was consistent with the instructional method and the desired learning outcomes. In each context, students were challenged to design, build and test a heart-lung machine to simulate the performance of a clinical cardiopulmonary bypass system. The project was easily modified according to the needs and constraints of each context. The project proved to be adaptable and transferrable to different contexts with different affective and cognitive learning objectives, assessment instruments, instructional strategy, student population, budget and timeframe of implementation.

\section{Acknowledgements}

The funding provided by the National Science Foundation DRK-12 program, R\&D: The INSPIRES Curriculum for Engineering and Technology Education grant number DRL 0822286, is gratefully acknowledged. After receiving a generous donation of supplies from the INSPIRES grant, Rowan University's project was supported by a grant from the National Science Foundation, DUE 1140631. The hollow fiber membrane units were graciously donated by Medtronic Incorporated. At University College Dublin, PBL was developed under the auspices of a University College Dublin Fellowship in Teaching \& Academic Development and with the assistance of University College Dublin Teaching \& Learning; the University College 
Dublin author gratefully acknowledges the support of Ms. Pat Connolly and Ms. Elena Tsalaporta in the development and implementation of the heart-lung machine project. 


\section{References}

1. Bureau of Labor Statistics, U.S.D.o.L. Occupational Outlook Handbook, Biomedical Engineers. 201529 December, 2015]; 2016-17 Edition:[Available from:

http://www.bls.gov/ooh/architecture-and-engineering/biomedical-engineers.htm.

2. Shallcross, D.C., Career Preferences for Undergraduate Chemical Engineering Students. Education for Chemical Engineers, 2006. 1(1): p. 30-38.

3. Kaplan, J.A., D.L. Reich, and J.S. Savino, Kaplan's Cardiac Anesthesia. 6th ed. 2011, St. Louis: Saunders.

4. $\quad$ Lillehei, W.C., Historical Development of Cardiopulmonary Bypass in Minnesota, in In Cardiopulmonary Bypass: Principles And Practice, G.P. Gravlee, et al., Editors. 2008, Lippincott Williams Wilkins: Philadelphia. p. 3-20.

5. Stoney, W.S., Evolution of cardiopulmonary bypass. Circulation, 2009. 119(21): p. 2844-53.

6. Hessel II, E.A., Circuitry and Cannulation Techniques, in Cardiopulmonayr Bypass: Principles and Practice, G.P. Gravlee, Editor. 2008, Lippencott, Williams Wilkins: Philadelphia.

7. Chatterjee, S. and A. Miller, Biomedical Instrumentation Systems. 2010: Cengage Learning.

8. Mclver, K., T.L. Merrill, and S. Farrell, A hands-on introduction to mass transfer using a hollow fiber blood oxygenator. Chemical Engineering Education, In review, 2015.

9. Stamatialis, D.F., et al., Medical applications of membranes: Drug delivery, artificial organs and tissue engineering. Journal of Membrane Science 308 134, 2008: p. 1-2.

10. Hessel, E.A. and L.H. Edmunds, Jr., Extracorporeal Circulation: Perfusion Systems, in Cardiac Surgery in the Adult, L.H. Cohn and L.H.J. Edmunds, Editors. 2003, McGraw-Hill: New York.

11. Tayama, E., S.A. Raskin, and Y. Nosè, Blood Pumps, in Cardiopulmonary Bypass: Principles and Practice, G.P. Gravlee, et al., Editors. 2000, Lippencott Williams and Wilkins: Philadelphia.

12. Haworth, W.S., The development of the modern oxygenator. The Annals of thoracic surgery, 2003. 76(6): p. S2216-9.

13. Brown, T.L., et al., Chemistry: the central science. 13th ed. 2014, Upper Saddle River: Prentice Hall.

14. Toenz, M., et al., Normothermia Versus Hypothermia During Cardiopulmonary Bypass: Controlled Trial. Annals of Thorac Surgery, 1995. 59(1 SRC - GoogleScholar): p. 137-143.

15. Wickramasinghe, S.R., C.M. Kahr, and B. Han, Mass transfer in blood oxygenators using blood analogue fluids. Biotechnology progress, 2002. 18(4): p. 867-73.

16. Prince, M.J. and R.M. Felder, Inductive teaching and learning methods: definitions, comparisons and research bases. Journal of Engineering Education, 2006. 95(2): p. 123-138.

17. Dym, C.L., et al., Engineering design thinking, teaching and learning. Journal of Engineering Education, 2005. 94(1): p. 103-120.

18. Mills, J.E. and D.F. Treagust Is problem-based or project-based learning the answer? Australasian Journal of Engineering Education, 2003.

19. Galand, B. and M. Frenay, L'approche par Problèmes et par Projets dans l'Enseignement Supérieur: Impact, Enjeux et Defies. 2005, Louvain-la- Neuve: Presses Universitaires de Louvain.

20. Spencer, J.A. and R.K. Jordan, Learner-centered approaches in medical education. British Medical Journal, 1996. 313: p. 275-283.

21. Vonder Haar, Z.D., T.M. Bayles, and J.M. Ross, Engineering in Healthcare: A Heart Lung System, in ASEE Annual Conference. 2011, ASEE Conferences: Vancouver, BC.

22. Davis, R., A project to design and build compact heat exchangers. Chemical Engineering Education, 2005. 39(1): p. 38-41. 
23. Bayles, T.M. A reflective writing assignment to engage students in critical thinking. in ASEE Annual Conference. 2013. Atlanta, GA: ASEE. 